\title{
Molecular characterization and morphological clustering of exotic early maturing rice (Oryza sativa L.) lines
}

\author{
M. M. Sarker, L. Hassan, M. M. Rashid ${ }^{1}$ and S. Seraj \\ Department of Genetics and Plant Breeding, Bangladesh Agricultural University, Mymensingh-2202, Bangladesh and \\ ${ }^{1}$ Farm Management Division, Bangladesh Rice Research Institute, Gazipur-1701, Email: kbdmanik@bau.edu.bd
}

\begin{abstract}
Characterization and variability analysis is important for the improvement of crop plant. This study aimed to evaluate the morphological and molecular variation of exotic early maturing rice (Oryza sativa L.) lines. A total of 32 exotic rice lines collected from different locations were genotyped and clustered using selected SSR markers. Based on morphological dendrogram, the lines were grouped into three clusters viz.I, II and III. Cluster I, cluster II and cluster III had 12, 11, 9 lines respectively. The results showed that the varieties were closely related belonging to the same cluster. DNA Markers namely Simple Sequence Repeats (SSR) is a useful tool for assessing genetic variations and resolving cultivar identities. Positive correlations were found between gene diversity, number of allele, the allele size range and the maximum number of repeats. Among the primers used RM147 identified more number of alleles and average PIC was 0.88. The UPGMA dendrogram based on Nei's (1972) genetic distance grouped the 32 rice lines into three major clusters. This result indicates that the line which formed grouped together, they are less diverse. A significant level of polymorphism based on morphological and molecular levels was observed. Being grouped into three clusters C1-4-11-7P-2P-1P and IR 79201-49-1-1-1 could be utilized as potential parents for the improvement of yield in early maturing rice lines.
\end{abstract}

Keywords: Early maturing rice, SSR markers, Cluster analysis, Genetic diversity

\section{Introduction}

Rice (Oryza sativa L.) is the staple food of more than $50 \%$ of the world's population (Aggarwal et al. 2002). The demand of rice increasing rapidly throughout the world. In Bangladesh, total crop production of 18.1 million tons and total demand is 35.3 million tons and cropping intensity is $183 \%$ (BBS, 2012). Therefore, to fill up the gap between production and demand, we need to increase cropping intensity nearly $300 \%$. Short duration rice is an important feature to increase cropping intensity. Breeding for earliness is one of the basic objectives in breeding programs. The increased attention to the development of short duration plant species for prolonged food production under different conditions indicates the necessity of performing breeding experiments (Martin et al. 2008; Khodadadi et al. 2011). Genetic distance between parents and clustering are essential to get benefit of transgressed segregation. Growth and development of agricultural resources is mostly depend on genetic diversity among different crop plants and it is estimated that not even $15 \%$ of the potential diversity has utilized. This implies that thousands of valuable allelic variations of traits of economic significance remain unutilized (Hossain et al. 2007). Therefore, lines of distinct genetic structure are a good promise for the future rice crop improvement. Thus identification of genotypes and their inter-relationships is essential and it can be done by molecular markers. Molecular markers are powerful tools to detect genetic diversity and to aid in the management of plant genetic resources (Virk et al. 2000; Song et al. 2003; Teixeira da Silva, 2005). Microsatellite is faster and easier for exploiting genetic polymorphism among different lines and populations compared with other markers. These markers can detect a significantly higher degree of polymorphism in rice (Ni et al. 2002, Okoshi et al. 2004). The objectives present study was to evaluate the morphological and molecular variation among 32 exotic early maturing rice lines.

\section{Materials and Methods}

The current research was carried out at Bangladesh Institute of Nuclear Agriculture (BINA), Mymensingh2202, during 2012 and 2013 seasons at Breeding field and Biotechnology laboratory.

\section{Plant materials}

Thirty two rice lines with diverse genetic background were used in this study. Of which thirty one were International Network for Genetic Evaluation of Rice (INGER) early maturing rice lines and one Bangladesh Institute of Nuclear Agriculture (BINA) developed short duration variety 'Binadhan-7' was used as check. 
Table 1. List of rice lines with origin

\begin{tabular}{|c|l|l|c|l|l|}
\hline SI No & \multicolumn{1}{|c|}{ Lines Name } & \multicolumn{1}{c|}{ Origin } & SI No & \multicolumn{1}{c|}{ Lines Name } & Origin \\
\hline 1 & IR 79246-105-2-2-4 & IRRI & 17 & BP 1018F-BB8-13-BB4 & INDONESIA \\
\hline 2 & IR 73718-26-1-2-5 & IRRI & 18 & IR 79525-20-2-2-2 & IRRI \\
\hline 3 & BP 10620F-BB4-13-BB8 & INDONESIA & 19 & IR 80285-34-3-3-2 & IRRI \\
\hline 4 & IR 79538-1-1-1-1 & IRRI & 20 & CT 18173-1-9-1-3-6-M & CIAT \\
\hline 5 & IR 76494-28-1-2-2 & IRRI & 21 & BP 10620F-BB4-2-BB4 & INDONESIA \\
\hline 6 & YN 2883-12-2-1 & MYANMAR & 22 & PSB RC 64 & INDIA \\
\hline 7 & AD 02207 & INDIA & 23 & IR 08N261 & IRRI \\
\hline 8 & BP 10620F-BB4-8-BB8 & INDONESIA & 24 & RATNAGIRI 2 & INDIA \\
\hline 9 & C1-4-11-7P-2P-1P & CIAT & 25 & MTU-1113 & INDIA \\
\hline 10 & IR 79201-49-1-1-1 & IRRI & 26 & KARJAT 5 & INDIA \\
\hline 11 & BP 10620F-BB4-12-BB8 & INDONESIA & 27 & KHAZAR & IRRI \\
\hline 12 & IR 82489-594-3-2-2 & IRRI & 28 & IR 59552-21-3-2-2 & CIAT \\
\hline 13 & CT 18509-10-6-1VI-2 & CIAT & 30 & IR 39809-26-3-3 & IRRI \\
\hline 14 & IR 74052-153-5-3-1-3 & IRRI & 31 & CT 18148-11-1-1-1-1-M & CIAT \\
\hline 15 & PSD RC 2 & IRRI & 32 & BINA DHAN 7 & BINA \\
\hline 16 & IR 08N293 & IRRI & & \\
\hline
\end{tabular}

\section{Design and data collection}

The experiment was laid out in a RCBD with three replications. The row to row and plant to plant distances were $20 \mathrm{~cm}$ and $15 \mathrm{~cm}$, respectively. The following data Plant height $(\mathrm{cm})$, Days to flowering, Days to maturity, Total tillers and effective tillers hill ${ }^{-1}$. Filled and unfilled grains panicle ${ }^{-1}, 1000$ seed weight $(\mathrm{g})$, Yield plant $^{-1}(\mathrm{~g})$ were collected from field from randomly selected 5 plants of each unit plot.

\section{Genotyping}

Modified CTAB mini prep was used for DNA extraction for 21day-old seedling (IRRI, 1997). Parental polymorphism survey was done with eight SSR markers. Out of 5 markers, three polymorphic SSR markers viz., RM147, RM202 and RM215 were showed polymorphic and clear bands. Each PCR reaction carried out with $15.0 \mu \mathrm{l}$ reactions containing $1.5 \mu \mathrm{l} 10 \mathrm{X}$ buffer, $0.75 \mu \mathrm{l}$ dNTPs, $1 \mu \mathrm{l}$ primer forward, $1 \mu \mathrm{l}$

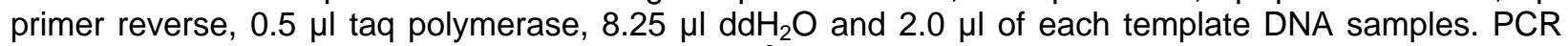
profile was maintained as initial denaturation at $94^{\circ} \mathrm{C}$ for $5 \mathrm{~min}$, followed by 34 cycles of denaturation at $94^{\circ} \mathrm{C}$ for $1 \mathrm{~min}$, annealing at $55^{\circ} \mathrm{C}$ for $1 \mathrm{~min}$ and polymerization at $72^{\circ} \mathrm{C}$ for $2 \mathrm{~min}$; and final extension by 7 min at $72^{\circ} \mathrm{C}$. Then electrophoresis in $1.5 \%$ agarose gel was done after polymorphism in the PCR products and stained in ethidium bromide.

\section{Primer test}

Five primers of random sequence were screened for amplification of the DNA sequences. The details of the primers are given in Table 2. A final subset of three primers exhibiting good quality banding patterns and sufficient variability were selected for further analysis.

Table 2. Random primers used in the present study for polymorphism survey

\begin{tabular}{|c|l|l|}
\hline Primer code & \multicolumn{1}{|c|}{ Forward Primer (Bases) } & \multicolumn{1}{c|}{ Reverse Primer (Bases) } \\
\hline RM47 & ACTCCACTCCACTCCCCAC & GTCAGCAGGTCGGACGTC \\
\hline RM147 & TACGGCTTCGGCGGCTGATTCC & CCCCCGAATCCCATCGAAACCC \\
\hline RM167 & GATCCAGCGTGAGGAACACGT & AGTCCGACCACAAGGTGCGTTGTC \\
\hline RM202* & CAGATTGGAGATGAAGTCCTCC & CCAGCAAGCATGTCAATGTA \\
\hline RM215* & CAAAATGGAGCAGCAAGAGC & TGAGCACCTCCTTCTCTGTAG \\
\hline
\end{tabular}

* Selected for SSR analysis in thirty two rice lines 


\section{Data Analysis}

Morphological cluster were constructed by using Stat Graphics Plus for Windows 3.0 (Statistical Graphics Crop. Rockville, USA). Molecular weights for microsatellite products were estimated with AlphaEaseFC 4 software. The summary statistics including the number of alleles per locus, major allele frequency, genetic diversity and polymorphism information content (PIC) values were determined by using POWER MARKER (version 3.23). The unweighted pair-group method with arithmetic mean (UPGMA) dendrogram was drawn by using the software TREEVIEW.

\section{Results and Discussion}

\section{Cluster analysis of morphological traits}

Ward's dendrogram: Dendrogram grouped of 32 lines of rice into three clusters (Fig 1). Binadhan-7 as control line is grouped in cluster II. with lowest (0.00) genetic distance, IR 79246-105-2-2-4, IR 73718-261-2-5, CT 18148-11-1-1-1-1-M, BP 1018F-BB8-13-BB4, AD 02207, BP 1018F-BB8-13-BB4,IR 80285-343-3-2, PSB RC 64, CT 18509-10-6-1VI-2, MTU-1113, KARJAT 5, KHAZAR, IR 39809-26-3-3were grouped in cluster I. IR 76494-28-1-2-2, IR 82489-594-3-2-2, IR 08N293, C 2-9-9-2P-1P-3P, IR 7952520-2-2-2, IR 79201-49-1-1-1, BP 10620F-BB4-12-BB8, IR 08N261, RATNAGIRI 2 were grouped on cluster III.

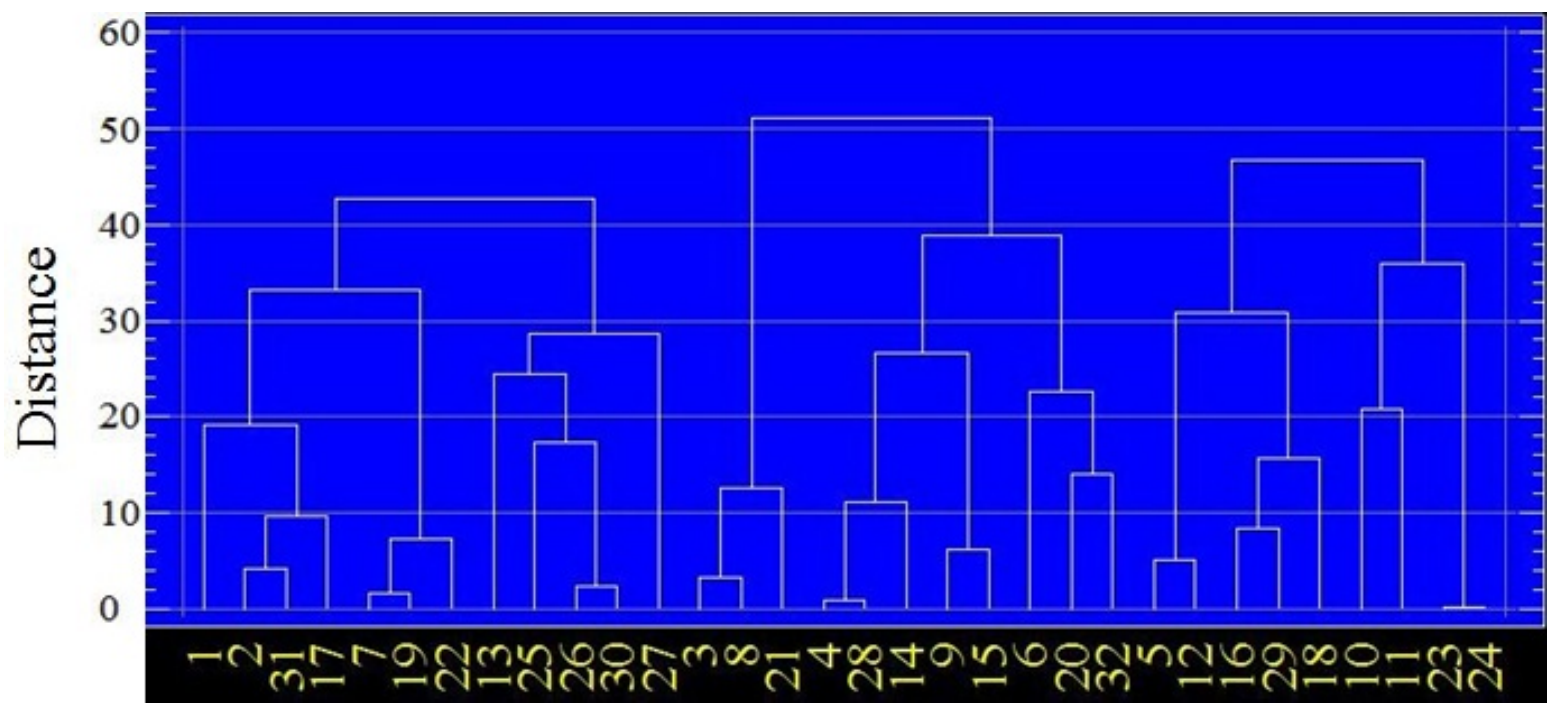

Fig.1. Dendrogram based on summarized data on differentiation among 32 lines of rice according to Ward's method

Genotyping through molecular markers: All the microsatellite loci (RM147, RM215 and RM202) amplified were found to be polymorphic. Using 3 primers across 32 varieties 45 allele were identified. The number of alleles ranged from eight to fourteen per locus. The locus RM147 had the highest number of alleles (14) and RM215 contain the number of alleles (12) while the locus RM202 had the lowest number of alleles (8) (Table 3). Yang et al. (1994) found up to 25 alleles for 10 microsatellite markers among 238 accessions of Indica and Japonica cultivars and landraces.

Table 3. Frequency and no. of alleles found by 3 SSR loci across 32 lines of rice

\begin{tabular}{|c|c|c|c|c|c|c|}
\hline Marker & Allele1 & Covariance & No. of alleles & Frequency & $2.5 \%$ I.b. & $97.5 \%$ u.b. \\
\hline RM147 & 157 & 0.00094 & 14 & 0.0313 & 0.5789 & 0.8947 \\
\hline RM215 & 431 & 0.00183 & 12 & 0.0625 & 0.5263 & 0.8947 \\
\hline RM202 & 427 & 0.00476 & 8 & 0.1875 & 0.4737 & 0.8421 \\
\hline
\end{tabular}




\section{Allelic and loci variation within the lines}

Gene diversity: According to Nei's (1972), the highest level of gene diversity value (0.90) was observed in loci RM215 and the lowest level of gene diversity value (0.81) was observed in loci RM147 with a mean diversity of 0.86 (Table 4). It was observed that marker detecting the fewer alleles showed lower gene diversity than those detected higher number of alleles which revealed higher gene diversity. The maximum number of repeats within the SSRs was also positively correlated with the genetic diversity Herrera et al. (2008), also observed that the gene diversity at each SSR locus was significantly correlated with the number of alleles detected, number of repeat motif and with the allele size range.

Allele size range: The size variation between the smallest and the largest allele at a given SSR locus was correlated with the number of alleles per locus. Thus, RM147 presented the smallest allele size range (129bp), while RM215 presented the largest allele size range (248bp) (Table 4).

PIC values: As a measure of the informativeness of microsatellites, the PIC values ranged from a low of 0.78 (RM202) to a high of 0.89 (RM215) and averaged 0.85 (Table 4).

Table 4. Data on repeat motif, PIC value and gene diversity (GD) found in 32 early maturing rice lines by 3 microsatellites (SSR)

\begin{tabular}{|c|c|c|c|c|c|c|}
\hline Locus & Repeat motif & $\begin{array}{c}\text { Allele Size } \\
\text { ranges }\end{array}$ & $\begin{array}{c}\text { Major Allele } \\
\text { Frequency }\end{array}$ & $\begin{array}{c}\text { Differences } \\
\text { (bp) }\end{array}$ & PIC & Gene Diversity \\
\hline RM147 & (TTCC)5(GGT)5 & $157-286$ & 0.22 & 129 & 0.88 & 0.89 \\
\hline RM215 & $(\mathrm{CT}) 16$ & $431-679$ & 0.16 & 248 & 0.89 & 0.90 \\
\hline RM202 & $(\mathrm{CT}) 30$ & $427-531$ & 0.31 & 104 & 0.78 & 0.81 \\
\hline Total & & & & & 2.56 & 2.60 \\
\hline Mean & & & 0.23 & & 0.85 & 0.86 \\
\hline
\end{tabular}
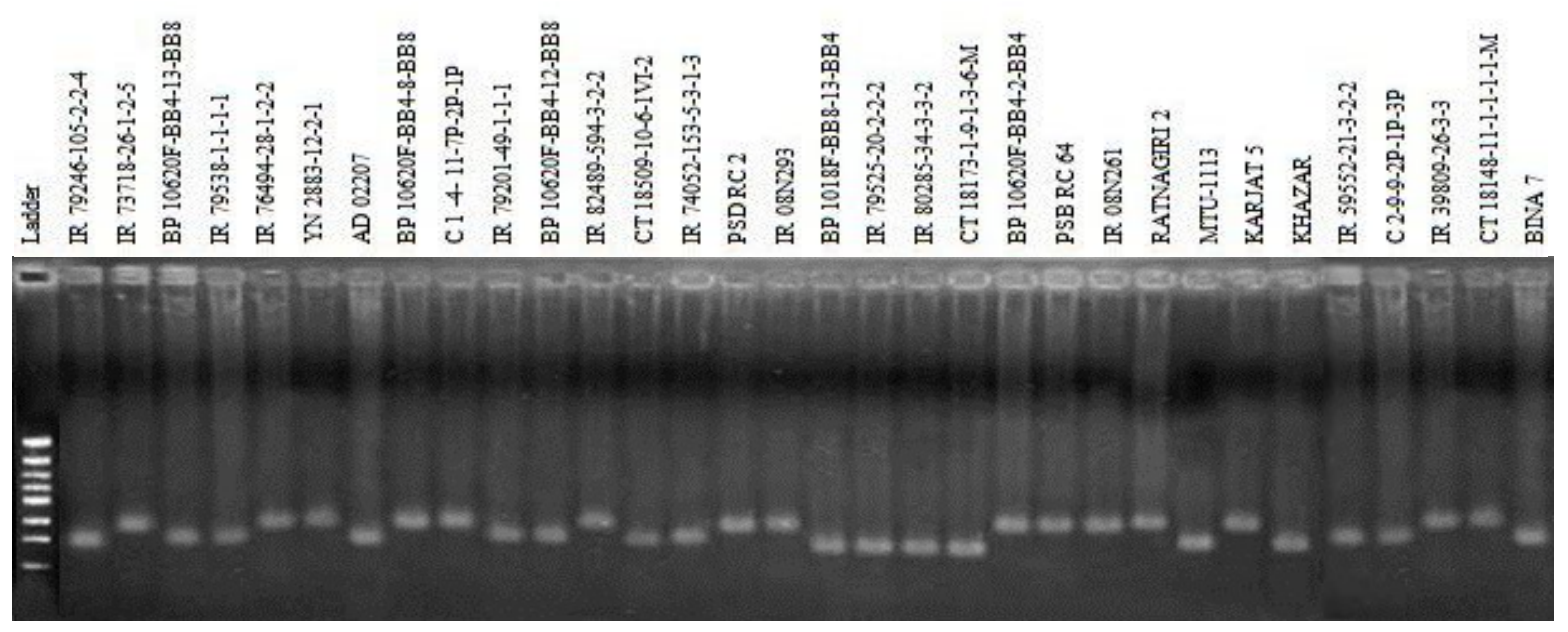

Fig. 2. Banding profiles of 32 rice genotype using primer RM147 


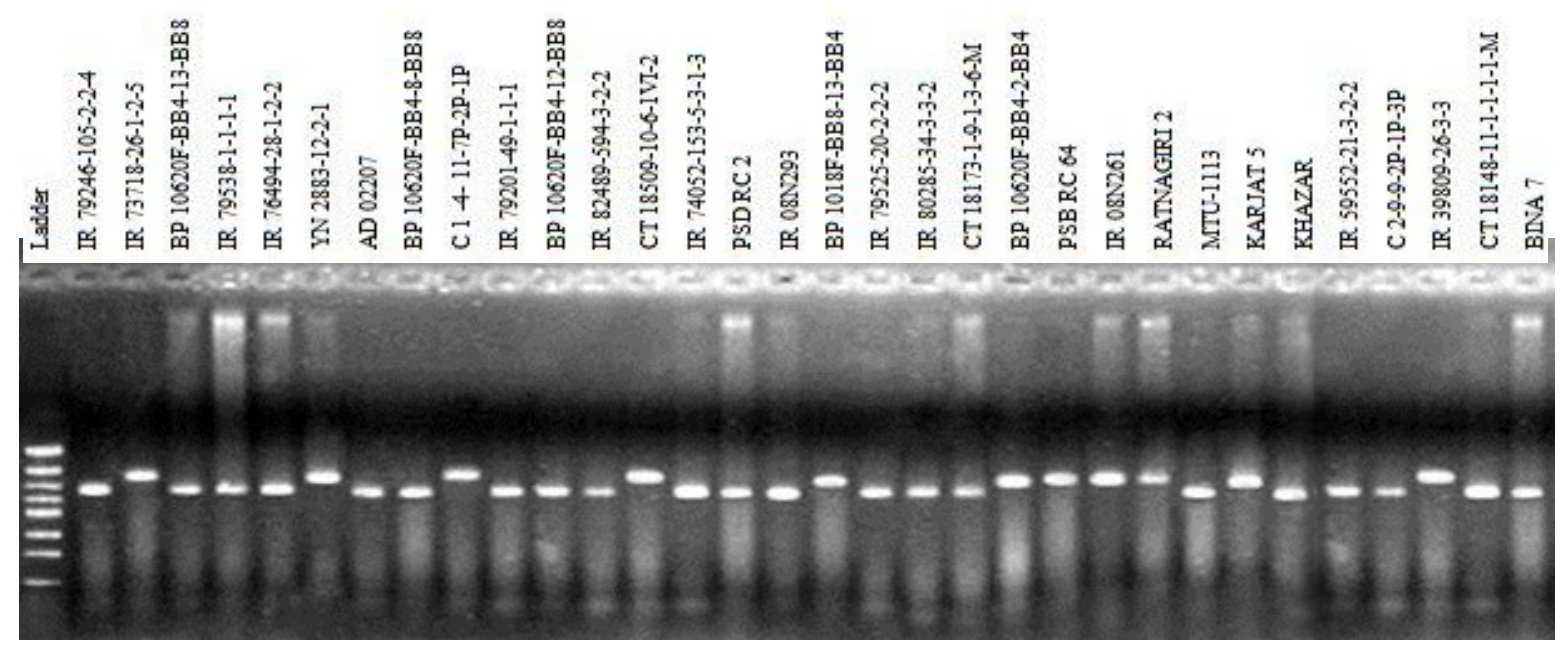

Fig. 3. Banding profiles of 32 rice genotype using primer RM202

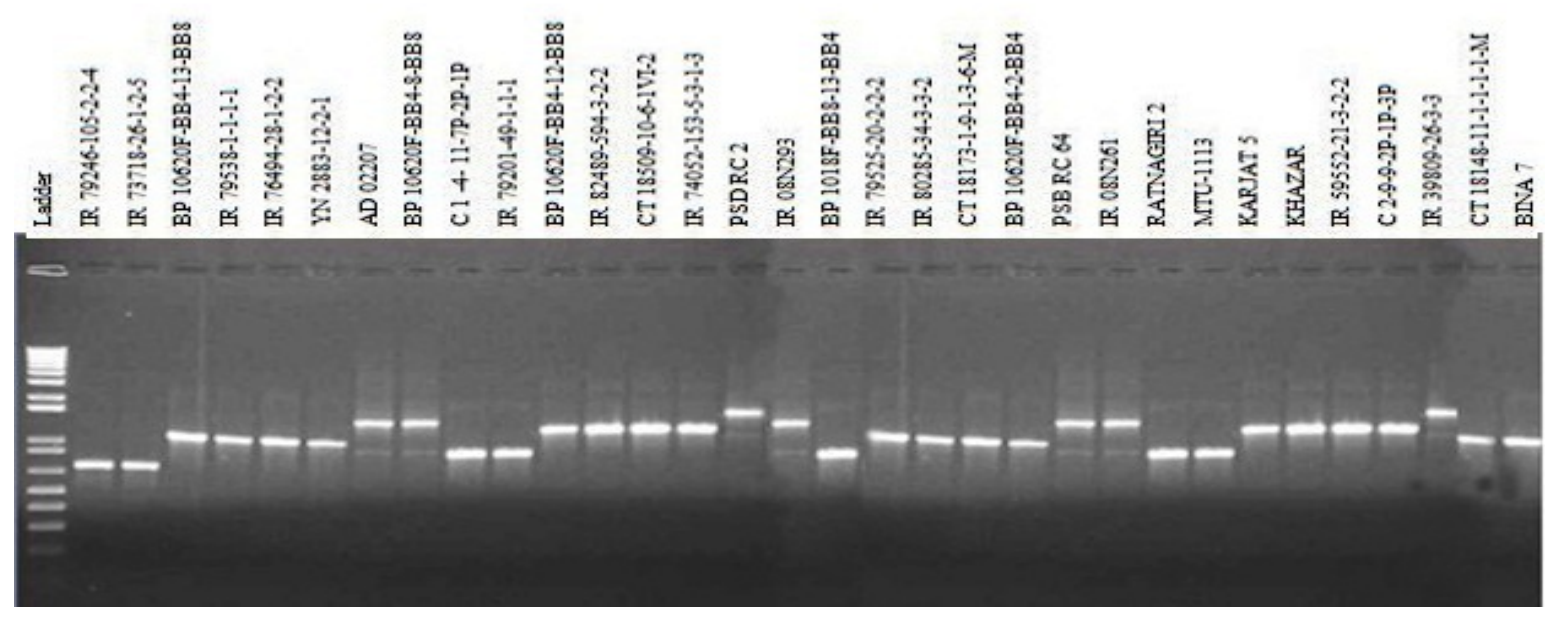

Fig. 4. Banding profiles of 32 rice genotype using primer RM215

\section{Genetic distance}

The values of pair-wise comparisons of Nei's (1972) genetic distance (D) between lines were computed from combined data for the 3 primers, ranged from 0.00 to 1.00 (Table 5). Higher genetic distance was observed between C1-4-11-7P-2P-1P vs IR 79201-49-1-1-1; IR 79246-105-2-2-4 vs IR 80285-34-3-3-2; AD 02207 vs BP 10620F-BB4-8-BB8; BP 10620F-BB4-2-BB4 vs Binadhan 7; KHAZAR vs IR 79525-20-22-2 lines pairs than the other lines combinations. The means of genetic distances between lines were used to evaluate the genetic diversity of different lines. Highly diversified lines could be useful in breeding programme to have potential genetic gains. 


\begin{tabular}{|c|c|c|c|c|c|c|c|c|c|c|c|c|c|c|c|c|c|c|c|c|c|c|c|c|c|c|c|c|c|c|c|c|}
\hline & 1 & 2 & 3 & 4 & 5 & 6 & & 8 & $y$ & 10 & 11 & 12 & 12 & & 15 & 16 & 17 & 18 & 19 & 20 & 21 & 22 & 23 & 24 & 25 & 26 & 27 & \begin{tabular}{|l|l}
28 & 2
\end{tabular} & 29 & 30 & 31 & \\
\hline 1 & 0.0 & 0.7 & 1.0 & 1.0 & 0.7 & 1.0 & 1.0 & 1.0 & \begin{tabular}{|l|l}
1.0 \\
\end{tabular} & 1.0 & 1.0 & 1.0 & 1.0 & 1.0 & 1.0 & 1.0 & 1.0 & 1.0 & 0.7 & 1.0 & 1.0 & 1.0 & 1.0 & & \begin{tabular}{|l|l|} 
\\
\end{tabular} & 1.0 & & & & & & \\
\hline & 0.7 & & & 1.0 & & 1.0 & 1.0 & 1.0 & 0.7 & 1.0 & 1.0 & 1.0 & 0.7 & 10 & 1.0 & 10 & 1.0 & 10 & 1.0 & \begin{tabular}{l|l}
1.0 \\
\end{tabular} & 1.0 & 1.0 & 1.0 & 0.7 & 1.0 & 1.0 & & & 1.0 & 0.7 & 1.0 & \\
\hline & 1.0 & 0 & & 0.7 & & 1.0 & 0.7 & 1.0 & 1.0 & 07 & 0.7 & 1.0 & 0.7 & & 1.0 & 10 & 0 & 07 & & 10 & 1.0 & 10 & 1.0 & 1.0 & & & & & 0.7 & 1.0 & 1.0 & \\
\hline 4 & 1.0 & 0 & & 0.0 & 1.7 & 1.0 & 1.0 & 1.0 & 1.0 & 1.0 & 1.0 & 1.0 & 1.0 & 0.7 & 1.0 & 10 & 1.0 & 1.0 & (6) & 7 & 1.0 & 1.0 & 1.0 & 1.0 & 1.0 & 10 & (8) & 0 & 1.0 & 1.0 & 1.0 & \\
\hline & 0.7 & 1.0 & & 0.7 & 0.0 & 1.0 & 1.0 & 1.0 & 0.7 & 1.0 & 1.0 & 1.0 & 1. & 1.0 & 1.0 & 1.0 & 1.0 & 1.0 & 0.7 & \begin{tabular}{|l|}
0.7 \\
\end{tabular} & 1.0 & 1.0 & 1.0 & \begin{tabular}{|l|l|}
0.7 \\
\end{tabular} & 1.0 & & 1.0 & & 1.0 & 1.0 & 1.0 & 1.0 \\
\hline 6 & 10 & & & 1.0 & & 0.0 & 10 & 1.0 & $\begin{array}{l}1.0 \\
\end{array}$ & & 10 & & & 10 & 10 & & 1.0 & & & & & & & & & & & & & 1.0 & 1.0 & \\
\hline 7 & & & & & & 0 & & 0.7 & 1.0 & & 0.3 & & & & 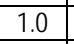 & & 1.0 & & 1.0 & $\begin{array}{l}0.7 \\
\end{array}$ & 1.0 & & \begin{tabular}{|l|}
0.7 \\
\end{tabular} & \begin{tabular}{|l|}
1.0 \\
\end{tabular} & 0.7 & & & & 0.3 & 11.0 & 0.7 & \\
\hline 8 & 1.0 & 1.0 & 1.0 & 1.0 & 1.0 & 1.0 & 0.7 & 0.0 & \begin{tabular}{|l|l}
1.0 \\
\end{tabular} & 1.0 & 1.0 & 1.0 & 1.0 & 1.0 & 0.7 & 0.3 & 1.0 & \begin{tabular}{|l|l}
0.7 \\
\end{tabular} & 1.0 & 1.0 & 1.0 & $\begin{array}{l}0.7 \\
\end{array}$ & \begin{tabular}{|l|}
0.7 \\
\end{tabular} & \begin{tabular}{|l|}
1.0 \\
\end{tabular} & 1.0 & 0.7 & \begin{tabular}{|l|l} 
\\
\end{tabular} & \begin{tabular}{|l|l|}
1.0 & 1 \\
\end{tabular} & 1.0 & \begin{tabular}{|l|l}
0.7 \\
\end{tabular} & \begin{tabular}{|l|l} 
\\
\end{tabular} & 0.7 \\
\hline 9 & & & & 1.0 & & 1.0 & 10 & 1.0 & \begin{tabular}{|l}
0.0 \\
\end{tabular} & & 1.0 & & & & 1.0 & & 1.0 & & & 1.0 & 1.0 & 1.0 & & \begin{tabular}{|l|}
0.0 \\
\end{tabular} & \begin{tabular}{|l|l}
1.0 \\
\end{tabular} & & & & & \begin{tabular}{|l}
0.7 \\
\end{tabular} & \begin{tabular}{|l|}
1.0 \\
\end{tabular} & \\
\hline 10 & 1.0 & 1.0 & 0.7 & 1.0 & 1.0 & 1.0 & 0.3 & 1.0 & \begin{tabular}{|l|}
0.7 \\
\end{tabular} & 0.0 & 0.3 & 0.7 & 0.7 & 0.7 & 1.0 & 1.0 & 1.0 & 1.0 & 1.0 & 0.7 & 1.0 & 1.0 & $\begin{array}{ll}1.0 \\
\end{array}$ & \begin{tabular}{|l|}
0.7 \\
\end{tabular} & 0.7 & 1.0 & 1.0 & 0.3 & \begin{tabular}{|l|}
0.3 \\
\end{tabular} & 1.0 & \begin{tabular}{|l|l|}
0.7 \\
\end{tabular} & 1.0 \\
\hline 11 & & & & & & & & & & & & & & & & & & & & & & & & & & & & & & & & \\
\hline$\frac{\frac{1}{12}}{12}$ & 1.0 & & & 1.0 & & 1.8 & $\overline{0 .}$ & 1.0 & 1.0 & & 0. & $\overline{0 .}$ & & & 1.0 & & 1.0 & & & 0.7 & 1.0 & 10 & & & 0.7 & & & & \begin{tabular}{|l|}
0.7 \\
\end{tabular} & \begin{tabular}{|l|l}
1.0 \\
\end{tabular} & 0.3 & \\
\hline 13 & 1.0 & & & 1.0 & 1.0 & 1.0 & 0.7 & 1.0 & 0.7 & 0.7 & 0.7 & 1.0 & O. & 0.7 & 1.0 & 1.0 & 1.0 & & 1.0 & 1.0 & 1.0 & 1.0 & 1.0 & 0.7 & 1.0 & 0.7 & 0.7 & 0.7 & \begin{tabular}{|l} 
\\
\end{tabular} & 0.7 & 1.0 & 1.0 \\
\hline 14 & 1.0 & & & 0.7 & & 1.0 & & 1.0 & 1.0 & & 0.7 & & & & & & & & & & & & & & & & & & & & & \\
\hline 15 & 1.0 & 1.0 & & 1.0 & 1.0 & 1.0 & 1.0 & 0.7 & 1.0 & 1. & 1.0 & 1.0 & 1.8 & 1. & 0.1 & 0. & 1.0 & 0.7 & & 1.0 & $\mid 0.7$ & 0.7 & 0.7 & 1.0 & 1.0 & 1.0 & 0.7 & 1.0 & 1.0 & \begin{tabular}{|l|}
0.7 \\
\end{tabular} & 1.0 & \\
\hline 16 & 1.0 & & & 1.0 & & 1.0 & 0.7 & 0.3 & 1.0 & & 1.0 & 1.0 & & & 0.7 & 0. & 1.0 & & & 1.0 & 1.0 & 0.7 & & 1.0 & & & 0.7 & & 1.0 & 1.0 & & 0.7 \\
\hline 17 & 1.0 & & & 1.0 & & 1.0 & 1.0 & 1.0 & 1.0 & & 1.0 & 1.0 & & & 1.0 & & 0.0 & & 1.0 & 1.0 & 1.0 & & & 1.0 & & & & & $\mid 1.0$ & \begin{tabular}{ll|}
1.0 \\
\end{tabular} & 1.0 & 1.0 \\
\hline 18 & 1.0 & 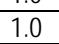 & & 1.0 & 1. & 1.0 & 1.0 & 0.7 & 1.0 & & 1. & 1. & & & 0 & 0 & 1.0 & 0. & & \begin{tabular}{|l|}
1.0 \\
\end{tabular} & 1.0 & 1.0 & & 1.0 & 1.0 & 1 & 0.7 & 1.0 & 1.0 & 1.0 & 1.0 & 0.7 \\
\hline 19 & 0.7 & & & 1.0 & & 1. & 1.0 & 1.0 & 1.0 & & 1. & 1. & & & 1.0 & 1.0 & 1.0 & 10 & 0. & 1.0 & 1.0 & 1.0 & & 1.0 & 0 & & 1.0 & 1.0 & 1.0 & 1.0 & 0.7 & 1.0 \\
\hline 20 & 1.0 & 1. & & 0.7 & & & 0 & 1.0 & 1.0 & & 0. & 0. & & & & & & & & \begin{tabular}{|l|}
0.0 \\
0.0
\end{tabular} & \begin{tabular}{|l}
1.0 \\
\end{tabular} & & & 0 & & & & & \begin{tabular}{|l|}
0.7 \\
\end{tabular} & \begin{tabular}{|l|l}
1.0 \\
\end{tabular} & 0.7 & \\
\hline 21 & 1.0 & 1.0 & 1. & 1.0 & 1. & 0. & 1.0 & 1.0 & 1.0 & & 1. & 1. & & & 0. & & & & & 1.0 & 0.0 & 0.3 & & 1.0 & 1.0 & & 1.0 & 1.0 & 1.0 & & & \\
\hline 22 & 1.0 & 1.0 & & 1.0 & & 1.0 & 0.7 & 0.7 & 1. & & 1 & 1. & & & 0.7 & 0. & 1. & & 1. & 1.0 & 0.3 & 0.0 & & 1.0 & 1.0 & 0.7 & 1.0 & 1.0 & 1.0 & 1.0 & 1.0 & \\
\hline 23 & 1.0 & 1.0 & 1.0 & 1.0 & 1.0 & 1.0 & 0.7 & 0.7 & 1.0 & 1 & 1.0 & 1. & & & 0.7 & & & & & 1.0 & 0.3 & 0.0 & & 0 & 1.0 & & 1.0 & 1.0 & 1.0 & 1.0 & 1.0 & \\
\hline 24 & 1.0 & 0. & & 1.0 & & 1.0 & 1.0 & 1.0 & 0.0 & & 1. & 1. & & & 1.0 & & & & & 1.0 & & & & & & & & & 1.0 & & 1.0 & \\
\hline 25 & 0.7 & & & 1.0 & & & & & & & & & & & & & & & & \begin{tabular}{|l|} 
\\
\end{tabular} & & & & & & & & & & 1.0 & & \\
\hline 26 & 1.0 & 1.0 & 1.0 & 1.0 & 1. & 1. & 1.0 & 0.7 & 1.0 & 1. & 1.0 & 1. & & 0 & 1. & 1 & 1 & & & 1.0 & & $\frac{1.0}{07}$ & & & $\frac{0.0}{10}$ & & 0.7 & & 1.0 & 0.7 & $\frac{1.0}{1.0}$ & \\
\hline 27 & 1.0 & 1. & 1. & 1.0 & 1 & 1. & & 0.7 & & & & & & & 0 & & & & & & & & & & & & & & & & & \\
\hline 28 & 1.0 & 1. & & 1.0 & & 1. & 0.3 & 1.0 & 1. & & 0. & & & & 1.0 & & & & & 0.7 & & & & & & & & & & & & \\
\hline 29 & 1.0 & 1. & 0. & $\frac{1.0}{1.0}$ & 1 & $\frac{x}{1 .}$ & 0. & $\frac{1.0}{1.0}$ & 1. & 0. & 0 & 0 & & & 1. & 1 & & & & \begin{tabular}{|l|}
0.7 \\
\end{tabular} & & 1.0 & & & 0.7 & & 1.0 & 0.3 & 0.0 & 1.0 & 0.7 & \\
\hline 30 & & & & & & & & & 0. & & & & & & & & & & & & & & & & & & & & & & & \\
\hline$\frac{5}{31}$ & $\frac{1.0}{1.0}$ & 1. & $\frac{1.0}{1.0}$ & $\frac{1.0}{1.0}$ & 1. & $\frac{1.0}{1.0}$ & $\begin{array}{l}0.0 \\
0.7\end{array}$ & 1.0 & $\frac{0.1}{1.0}$ & & 0.7 & 0.3 & 1. & 0 & 1. & & 1 & & & 0.1 & & & & & & & 1.0 & & 0.7 & & & \\
\hline 32 & 1.0 & 1.0 & 1.0 & 0.7 & 1.0 & 0.7 & & \begin{tabular}{|l}
0.7 \\
\end{tabular} & 1.0 & 1.0 & 1.0 & 1.0 & 1.0 & 0.7 & 0.7 & & & & & & & & & & & & & & & & & \\
\hline
\end{tabular}

Here, 1=IR 79246-105-2-2-4, 2=IR 73718-26-1-2-5, 3=BP 10620F-BB4-13-BB8, 4=IR 79538-1-1-1-1, 5=IR 76494-28-1-2-2, 6=YN 2883-12-2-1, 7=AD 02207, 8=BP 1062OF-BB4-8-BB8, 9=C1-4-11-7P-2P-1P, 10=IR 79201-49-1-1-1, 11=BP 10620F-BB4-12-BB8,12=IR 82489-594-3-2-2, 13=CT 18509-10-6-1VI-2, 14=IR 4052-153-5-3-1 $3,15=\quad P S D$ RC 2, $16=I R$ 08N293, 17=BP 1018F-BB8-13-BB4, 18=IR 79525-20-2-2-2, 19=IR 0285-34-3-3-2, 20=CT 18173-1-9-1-3-6,M, 21=BP 10620F-BB4-2-BB4, 22=PSB RC 64, 23=IR 08N261, 24= ATNAGIRI 2, 25=MTU-1113, 26=KARJAT 5, 27=KHAZAR, 28=IR 59552-21-3-2-2, 29=C2-9-9-2P-1P-3P, 30=IR 39809-26-3-3, 31=CT 18148-11-1-1-1-1-M and 32=Binadhan-7 


\section{UPGMA Dendrogram}

Thirty two lines of the experiment were used to make dendrogram based on Nei's (1972) genetic distance using Unweighted Pair Group Method of Arithmetic Means (UPGMA). In this study 32 rice lines have been differentiated into three main clusters. The clusters were separated into several sub-cluster.

The dendrogram showed that the lines were closely related belonging to the same cluster while the lines KHAZAR, IR 59552-21-3-2-2 and C1-4- 11-7P-2P-1P belonging to different cluster suggesting that these varieties were genetically diverse in origin. The dendrogram revealed that the lines that are derivatives of genetically similar type clustered together.

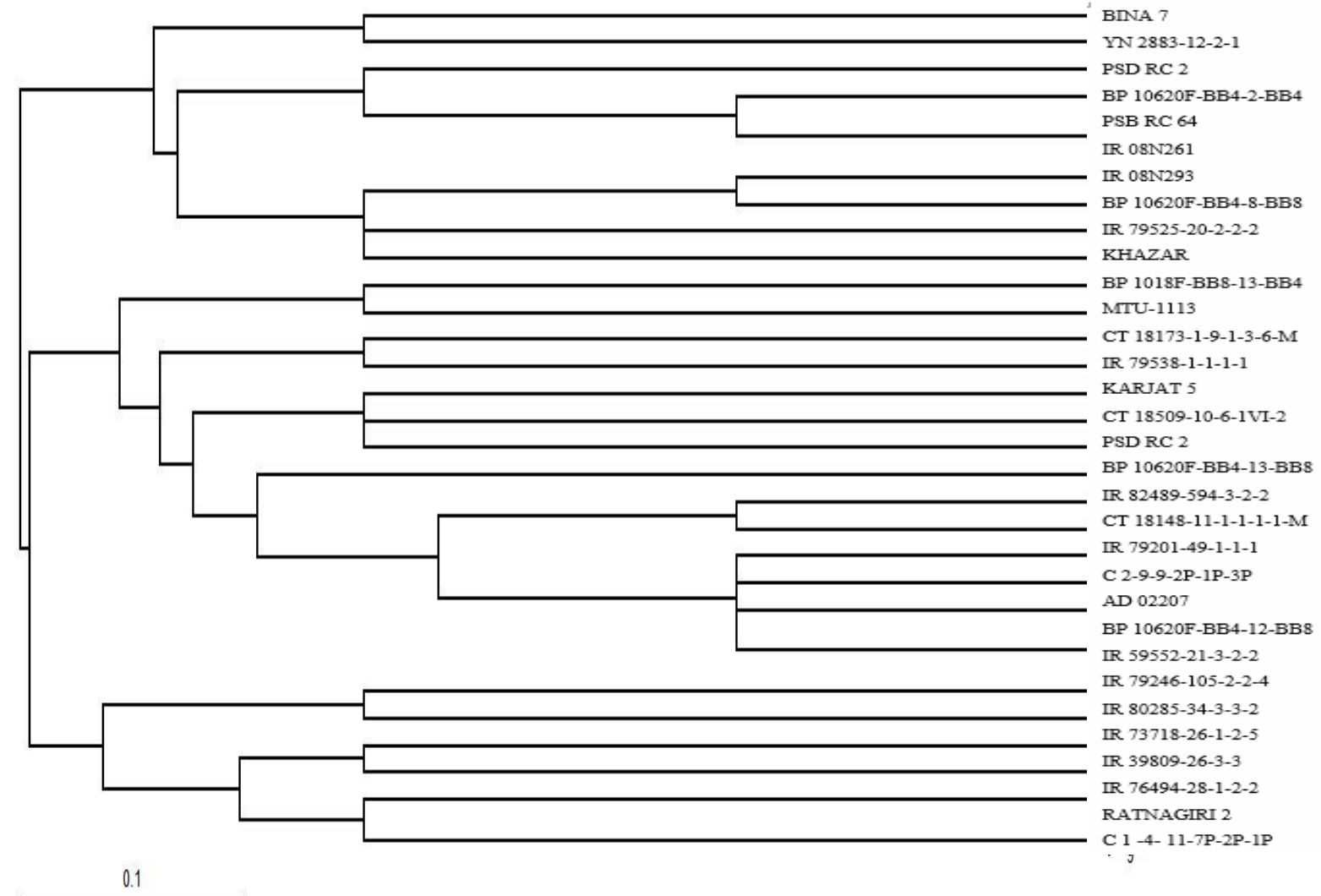

Fig. 5. UPGMA dendrogram based on Nei's (1972) genetic distance, summarizing the data on differentiation among 32 rice lines according to microsatellites marker analysis

\section{Conclusion}

The lines were grouped into three clusters viz.I, II and III for both morphological and molecular (UPGMA) dendrogram analysis. Hybridization among lines drawn from these widely divergent clusters with high yield potential would likely to produce heterotic combinations and wide variability in segregating generations. The results of molecular study showed that 14 alleles were identified by the each RM147, 12 and 8 alleles were identified by RM215 and RM202 respectively. As a measure of the informativeness of microsatellites, the PIC values ranged from a low of 0.78 (RM202) to a high of 0.89 (RM215) and averaged 0.85. According to Nei's (1972), the highest level of gene diversity value (0.90) was observed in loci RM215 and the lowest level of gene diversity value (0.81) was observed in loci RM202 with a mean diversity of 0.86 . The identification and understanding of higher molecular diversity will be utilized in future breeding programme of developing more early maturing rice varieties. The use of more number of markers would be efficient to characterize the lines than used for the present study. 


\section{Acknowledgements}

This work was supported by a grant from the Biotechnology laboratory of Plant Breeding Division, Bangladesh Institute of Nuclear Agriculture (BINA), Mymensingh.

\section{References}

Aggarwal, R.K., Shenoy, V.V., Ramadevi, J., Rajkumar, R. and Singh, L. 2002. Molecular characterization of some Indian Basmati and other elite rice genotypes using fluorescent AFLP. Theor. Appl. Gent. 105: 680-690.

BBS (Bangladesh Bureau of Statistics). 2012. Monthly Statistical Bulletin of Bangladesh. Stat. Div., Minst. Planning, Bangladesh Bur. Stat, Govt. People's Repub. Bangladesh, Dhaka.p. 182.

Herrera, T.G., Duque, D.P., Almeida, I.P., Nunez, G.T., Pieter's, A.J., Martinez, C.P. and Tohme, J.M. 2008. Assessment of genetic diversity in Venezuelan rice cultivars using Simple Sequence Repeats markers electron. J. Biotech. 11(5): 215-226.

Hossain, M.Z., Rasul, M.G., Ali, M.S, Iftekharuddaula, K.M., Mian, M.A.K. 2007. Molecualar characterization and genetic diversity in fine grain and aromatic landraces of rice using microsatellite markers. Bangladesh J. Genet. Pl. Breed., 20(2): 1-10.

IRRI (International Rice Research Institute). 1997. Rice Almanae. IRRI-WARDA-CIAT, Los Baños, Laguna, Philippines. P. 18.

Khodadadi, M., Fotokian, M.H. and Miransari, M. 2011. Genetic diversity of wheat (Triticum aestivum L.) genotypes based on cluster and principal component analyses for breeding strategies. Australian Journal of Crop Science, 5(1):17-24.

Martin, E., Cravero, V., Espósito, A., Anido, F.L., Milanesi. L. and Cointry, E. 2008. Identification of markers linked to agronomic traits in globe artichoke. Aus. J. Crop Sci., 1(2): 43-46.

Nei's, M. 1972. Genetic distance between populations. American Naturalist 106: 283-292.

$\mathrm{Ni}$, J., Colowit, P.M. and Mackill, D.J. 2002. Evaluation of genetic diversity in rice subspecies using microsatellite markers. Crop Sci. 42: 601-607.

Okoshi, M., Hu, J., Ishikawa, R. and Fujimura, T. 2004. Polymorphic analysis of landrace of Japanes rice using microsatellite markers. Breed. Res. 6: 125-133.

Song, Z.P., Xu, X., Wang, B., Chen, J.K. and Lu, B.R. 2003. Genetic diversity in the northernmost Oryza rufipogon populations estimated by SSR markers. Theor. Appl. Genet., 107: 1492-1499.

Teixeira, da Silva JA. 2005. Molecular markers for phylogeny, breeding and ecology in agriculture. In: Thangadurai D, Pullaiah T, Tripathy L (Eds) Genetic Resources and Biotechnology (Vol. III), Regency Publications, New Delhi, India, p: 221-256.

Virk, P.S., Newbury, J.H., Bryan, G.J., Jackson, M.T. and Ford-Lloyd, B.V. 2000. Are mapped or anonymous markers more useful for assessing genetic diversity? Theor. Appl. Genet., 100: 607-613.

Yang, Z., Goldman, N. and Friday, A. 1994. Comparison of models for nucleotide substitution used in maximum likelihood phylogenetic estimation. Mol. Biol. Evol. 11:3 16-324. 